\title{
Review
}

Neuro

\section{Future Trends and the Economic Burden of Dementia in Manitoba: Comparison with the Rest of Canada and the World}

\author{
Aida Adlimoghaddam ${ }^{a, b}$ Banibrata Roy ${ }^{c, d}$ Benedict C. Albensi ${ }^{a, b}$ \\ ${ }^{a}$ Division of Neurodegenerative Disorders, St. Boniface Hospital Research, Winnipeg, MB, Canada; ${ }^{b}$ Department \\ of Pharmacology and Therapeutics, Faculty of Health Sciences, College of Medicine, University of Manitoba, \\ Winnipeg, MB, Canada; ' Department of Institutional Research and Assessment, Community College of Aurora, \\ Aurora, CO, USA; ${ }^{d}$ Department of Community Health Sciences, Faculty of Health Sciences, College of Medicine, \\ University of Manitoba, Winnipeg, MB, Canada
}

\section{Keywords}

Dementia $\cdot$ Manitoba $\cdot$ Canada $\cdot$ Statistics $\cdot$ Gender $\cdot$ Age $\cdot$ Healthcare costs

\begin{abstract}
Dementia is a growing public health concern in Canada. This epidemic is linked to huge human and economic costs. The number of Manitobans (65+) with dementia in $2045(47,021)$, representing $2.58 \%$ of the Manitoban population, will be 2.3 times that of the year $2015(20,235)$. The number of cases of dementia in Manitoba grew by 20.7\% from 2015 to 2025, $68.16 \%$ from 2015 to 2035 and at an alarming rate of $125 \%$ from 2015 to 2045. Importantly, the total economic burden of dementia in Manitoba is close to one billion USD and is expected to grow more than 28 billion USD during the year 2038. The focus of this review is to compare dementia rates and the financial burden of dementia in Manitoba with the rest of Canada and the world from 2012 to 2048.
\end{abstract}

(c) 2018 S. Karger AG, Basel

\section{KARGER}

(c) 2018 S. Karger AG, Basel

E-Mail karger@karger.com

www.karger.com/ned

\section{Introduction}

In general, dementias are progressive, irreversible, neurodegenerative disorders that typically begin with a minor loss of intellectual functioning and sometimes progress to severe cognitive impairment. Eventually dementia patients become completely dependent on other people for personal care [1]. Dementia is actually an umbrella term, and several forms exist such as Alzheimer's disease [2], vascular dementia [3, 4], frontotemporal dementia [5], Lewy body dementia [6], dementia associated with Parkinson's disease, and mixed dementia [7]. Current studies are investigating whether each form of dementia has its own cause or results from multiple causes. Dementia affects not only the patient but also has a profound effect on relatives, caregivers, and the society as a whole. Overall, dementia is a costly disease in terms of both economic loss and personal suffering. There is currently no cure for Alzheimer's dementia. However, 
Table 1. Dementia statistics at a glance

\begin{tabular}{lll}
\hline & 2015 count & Future count \\
\hline Manitoba & 20,760 as of 2015 by Alzheimer Society report [97] & $\begin{array}{l}34,097 \text { by 2038 [97] } \\
40,700 \text { by 2038 - MBS report [26] }\end{array}$ \\
\hline Canada & 74,900 as of 2015 by our MBS report [26] & 1.4 million by 2031 [97] \\
\hline World-wide & 47.5 million as of 2015 [98] & 75.6 million by 2030 [98] \\
& & 135.5 million by 2050 [98] \\
\hline
\end{tabular}

some pharmacological therapies can improve some symptoms of dementia and/or slow the progression of the disease in some individuals $[8,9]$. It is believed that the efficacy of treatment could be optimized if interventions were initiated in the early or prodromal stage of the disease.

\section{Dementia Worldwide}

A study by Alzheimer's Disease International (ADI, www.alz.co.uk) has reported the following estimated percentages of people living with dementia, as of 2015, by geographic region: North America (6.4\%), Western Europe (5.4\%), Latin America (4.6\%), Australia and New Zealand (4.3\%), Eastern Europe (3.9\%), North Africa (3.6\%), Middle East (3.6\%), Indonesia, Thailand, Sri Lanka (2.7\%), India and South Asia (1.9\%) [10]. Therefore, global estimates predict 47.5 million worldwide are living with dementia, which is more than the population of Canada. This number is expected to rise considerably in the years ahead, reaching 135 million by 2050 [11] (Table 1). Available epidemiological studies also estimated the annual diagnosis of new dementia cases to be greater than 7.7 million people. This suggests that one new dementia case is identified globally almost every $4 \mathrm{~s}$ [12]. Moreover, the number of individuals living with dementia is projected to double by 2030 and subsequently triple by 2050 [10, 13]. Although there is a similar pattern in increases in diagnosed dementia cases around the world, the rate of increase region-by-region does vary [14]. For example, in 2040 , it is estimated that the rate of dementia cases is expected to rise by $100 \%$ in developed countries; however, in Southern Asia, China, India, and Western Pacific neighbors, rates are expected to increase by $300-400 \%$ during this period [10]. The significant increased prevalence of dementia must be taken serious- ly as a worldwide health problem. Any future action plans will need to consider how the prevalence of dementia will change worldwide.

\section{Dementia in Canada}

The Canadian Study of Health and Aging (CSHA) proposed that dementia prevalence is different across various regions in Canada $[15,16]$. However, in Ontario, the low prevalence of dementia in men appeared to be due to differences in the use of diagnostic methods [15]. Variances in socio-economic conditions, such as low educational attainment as well as lower income, also likely contribute to higher dementia rates in some regions as compared to others $[17,18]$. The Alzheimer Society of Canada (www.alzheimer.ca) compared 4 reports that provided estimates of present and future prevalence of dementia in Canada: The $\mathrm{Na}$ tional Population Health Study of Neurological Conditions, 2014 (NPHSNC); the CSHA, 1994; the Alzheimer Society of Canada, 2010 (Rising Tide); and the Mental Health Commission of Canada, 2011 (MHCC; Table 2). It is important to note that different reporting sources used various estimation methods on the prevalence of dementia [19]. In addition, variations among studies were related to the definition of dementia adopted, testing instruments used to measure dementia status, population surveys versus administrative databases, and the range of ages. For example, the CSHA estimated a higher prevalence of dementia as compared to NPHSNC, where the reason appeared to be based on inclusion of health administrative data. The CSHA and Rising Tide studies included individuals who do not have access to the healthcare system, whereas the NPHSNC and MHCC excluded such people [19]. In the MHCC report, mild cognitive impairment (MCI) individuals were counted together with dementia cases. However, some estimates stated that $39-60 \%$ of individuals with MCI will progress to dementia [20-23]. In other reports where
Adlimoghaddam/Roy/Albensi 
Table 2. Estimated dementia prevalence in Canada from 4 sources

\begin{tabular}{|c|c|c|c|}
\hline $\begin{array}{l}\text { Sources of report and age of individuals } \\
\text { with dementia }\end{array}$ & Year 2011 & Year 2021 & Year 2031 \\
\hline NPHSNC [99] ( $\geq 40$ years old) & 340,170 & 461,651 & 673,991 \\
\hline CSHA [15] ( $\geq 65$ years old) & 480,000 & 600,000 & 780,000 \\
\hline Rising Tide [100] (all ages) & 521,280 & 687,552 & 923,763 \\
\hline MHCC [44] ( $\geq 65$ years old $)$ & 747,129 & $1,024,465$ & $1,435,923$ \\
\hline
\end{tabular}

MCI and dementia are included together, the estimation would be approximately $50 \%$ more than if dementia alone was included in the estimate. The MHCC, unlike the other 3 reports, included the highest estimates of dementia prevalence [24]. This is likely because it included MCI in their estimations. Unlike the Riding Tide study, which included estimation of dementia prevalence for all ages, the NPHSNC, CSHA, and MHCC studies presented estimation of dementia in a limited range of ages. In comparison to the other 3 reports, CSHA appeared to be the best populationbased data source to use as a basis to build estimates given the age categories included [19]. In 2016, CSHA estimated there are 564,000 individuals living with dementia in Canada. By 2033, it is estimated that the dementia prevalence will increase significantly to 986,000 in Canada. Table 3 shows the number of individuals with dementia in Canada for the years 2014 and 2033.

\section{Dementia in Manitoba}

According to the CSHA study, the number of Manitobans affected by Alzheimer's disease and other forms of dementia is rising sharply, especially for those aged 65 and above. In 2011, according to the Alzheimer Society of Canada, 20,760 Manitobans were affected with Dementia. This number is growing at an alarming rate and is expected to rise to 40,700 by 2038 - a $60 \%$ increase [ 25 , $26]$. The overall number of cases of dementia in Manitoba is expected to grow by $20.7 \%$ from the 2015 to 2025 , $68.16 \%$ from 2015 to 2035 , and $125 \%$ from 2015 to 2045 (Fig. 1). However, it should also be noted that these age groups are increasing in number as well. Nevertheless, Manitoba's healthcare systems need to be prepared, both from social and economic perspectives. In the near future, increases in dementia cases will also have a critical impact on caregivers and supportive services, which will be challenging to deal with.

With regard to any racial-ethnic disparities in dementia across Manitoba, almost nothing has been published. How-

Future Trends and the Economic Burden of Dementia in Manitoba
Table 3. Estimated prevalence of dementia by Alzheimer Society of Canada from 2014 to 2033

\begin{tabular}{ll}
\hline Year & Prevalence \\
\hline 2014 & 514,000 \\
2015 & 539,000 \\
2016 & 564,000 \\
2017 & 587,000 \\
2018 & 614,000 \\
2019 & 638,000 \\
2020 & 663,000 \\
2021 & 688,000 \\
2022 & 713,000 \\
2023 & 738,000 \\
2024 & 763,000 \\
2025 & 788,000 \\
2026 & 813,000 \\
2027 & 838,000 \\
2028 & 863,000 \\
2029 & 887,000 \\
2030 & 912,000 \\
2031 & 937,000 \\
2032 & 962,000 \\
2033 & 987,000 \\
\hline
\end{tabular}

ever, approximately $14 \%$ of the total Indigenous population in Canada lives in Manitoba. In fact, Statistics Canada (www.statcan.gc.ca) 2016 census states there are 223,310 Indigenous people in Manitoba out of 1,673,780 across Canada [27]. Winnipeg actually has the largest Indigenous population as compared to other Canadian cities. According to Diabetes Canada (www.diabetes.ca), Aboriginals are at higher risk of contracting type 2 diabetes $[28,29]$. In particular, studies show that modifiable risk factors such as diabetes are strongly correlated with increased AD risk [30]. Indigenous peoples in Canada have a higher prevalence of modifiable risk factors as compared to non-Indigenous subpopulations [30]. However, these differences are seen more in Indigenous people who live on reserves. Therefore, it is highly likely that Indigenous people in Manitoba are at greater risk for dementia than other subpopulations. 


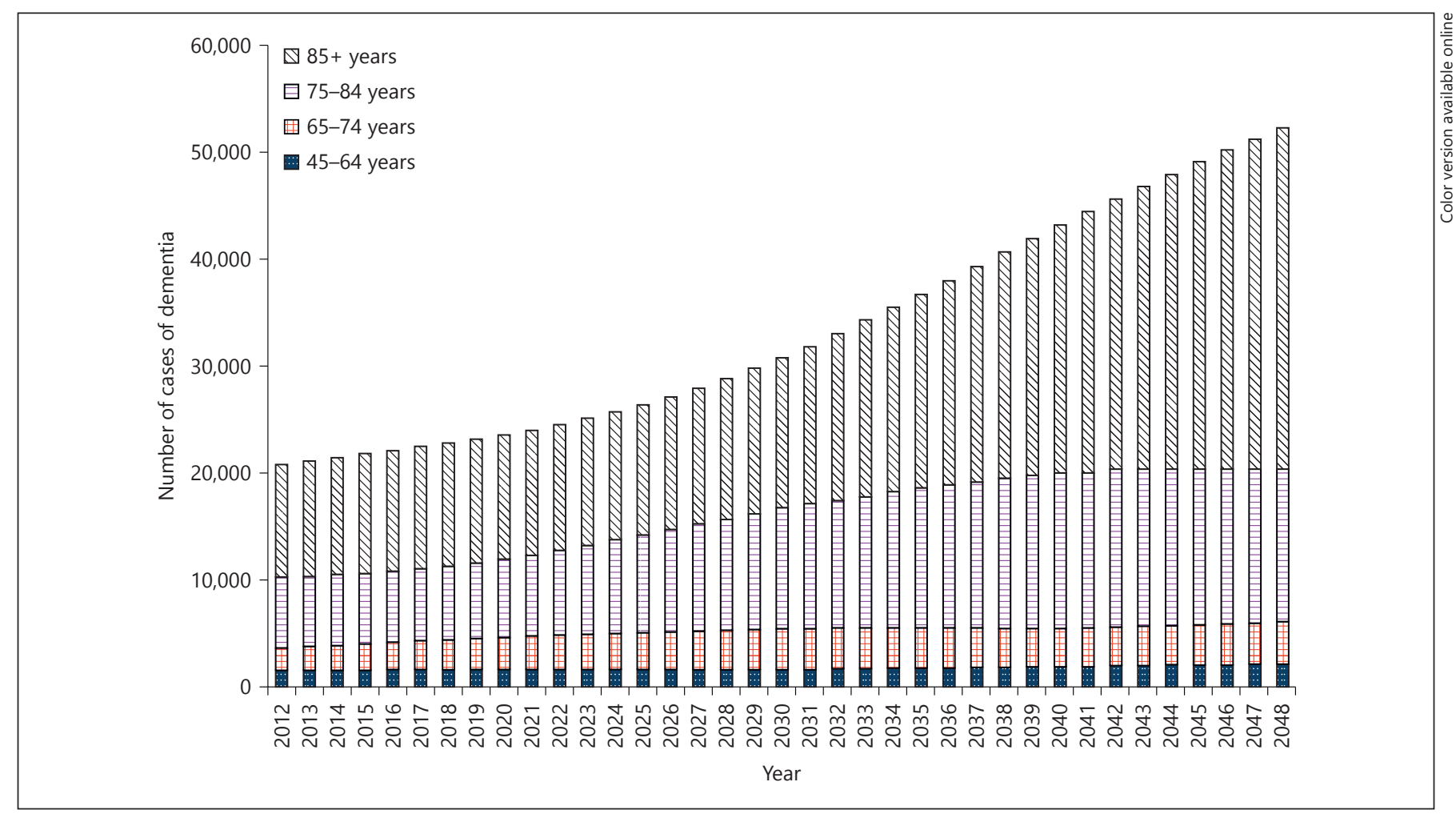

Fig. 1. Projection of dementia statistics of Manitoba (45+) gender-wise in both sexes.

\section{Caregivers and Dementia}

It is likely that the rising numbers of elderly individuals with dementia will place greater demands on caregiving systems [31]. Two types of care systems (formal and informal) are available for most individuals with dementia. Formal care is provided by organizations with paid/ volunteer workers. Informal care is delivered by family, friends, or neighbors. According to Statistics Canada, approximately $85 \%$ of patients with dementia are cared for, at least in part, at home by family members - mostly spouses or by adult children [32]. Approximately $75 \%$ of caregivers were female, $23 \%$ of caregivers were the person's wife, $12 \%$ were the husband, $37 \%$ were an adult child ( $28 \%$ daughters, $9 \%$ sons), and $23 \%$ were friends and/or relatives [33-36]. Almost $43 \%$ of patients with dementia received at least some type of formal care. Approximately $15 \%$ of patients with dementia did not receive any care (formal or informal) based on their financial situation and availability of caregivers [36]. According to the Alzheimer Society of Canada, in 2011, informal caregivers spent over 444 million unpaid hours of caring for their family member(s) with dementia [37]. This represents 11 billion dollars in lost income. By 2040, this number is expected to increase by 1.2 billion unpaid hours per year [19]. Therefore, dementias have an enormous impact on individuals with the disease as well as their families.

In 2015, the Winnipeg Regional Health Authority Home Care System reported over 20,000 individuals with dementia accessed the home care service [38]. Among these individuals, $76 \%$ of them were $\geq 65$ and $61 \% \geq 75$ years old [38]. The proportion of Manitoba seniors is increasing sharply and the increasing age of the population in the next few decades is associated with increased need for formal care support. Overall, the number of caregivers is crucial not only to care recipients but also to the healthcare system and the economy.

\section{Economic Impact of Dementia}

Dementias are a serious global health challenge and also an economic challenge for all governments [39]. According to the World Health Organization (WHO, www. who.int) and the World Alzheimer Reports from Alzheimer's Disease International, the total global cost associated with treating and supporting individuals with 
Table 4. Dementia costs at a glance in USD

\begin{tabular}{lll}
\hline 2011 & $\begin{array}{l}\text { Future dollars on an } \\
\text { annual basis (adjusted for inflation) }\end{array}$ \\
\hline $\begin{array}{ll}\text { Manitoba } \\
\text { Canada }\end{array}$ & USD 1 billion [48] & USD 28 billion by 2038 [48] \\
World-wide & USD 33 billion [101] & USD 293 billion by 2040 [101] \\
\hline
\end{tabular}

dementia was more than $1 \%$ of the world gross domestic product (GDP) or 604 and 818 billion USD in 2010 and 2015 respectively (Table 4) [40,41]. This estimate contains the cost of providing health and social care and also includes the reduction or loss of income in individuals with dementia and their caregivers [39]. The majority of costs are incurred in high-income countries $(1.4 \%$ of GDP) compared to low and middle-income countries $(0.2 \%)$ [42]. In Canada, the combined direct costs (medical) and indirect costs (lost earnings) are 33 billion USD annually, which will increase significantly to 293 billion USD annually by 2040 (Table 4) [19, 43]. Direct health expenses related to dementia can accrue within the formal health care system (i.e., cost of prescription medication, long-term care staff costs, support staff costs, longterm care administrative costs, physician and hospital costs) or outside the formal health care system (cost of over-the-counter medications, long-term care accommodation and out-of-pocket expenses) [25]. Indirect costs have no direct connection to dementia but are a result of it. The indirect costs consist of the loss in wages resulting from disability associated with dementia and/or in corporate profits that result from the reduction in labor productivity for both the individuals with dementia who are working at the time of symptom onset and providers of informal care.

The public system only presents a portion of the total monetary costs of dementia. In order to obtain an accurate measure of costs, indirect costs (informal caregiving) should be counted in addition to direct costs. Different population-based studies utilized different types of costs, methods, and data sources in the way they attributed costs to dementia. Therefore, estimated costs of dementia from different reports are varied. In predicting the costs involved in caring for individuals with dementia, the MHCC and Rising Tide studies include direct costs in their analyses, while the Economic Burden of Illness in Canada and CSHA studies include indirect/informal costs in their analyses [15, 43-46]. Unlike other reports, the Population Health Study of Neurological Conditions

Future Trends and the Economic Burden of Dementia in Manitoba
(PHSNC) is the only available study that includes direct, indirect, and intangible costs [47]. Analysis by the NPHSN, showed that total health care system costs and out-of-pocket costs of caring for individuals with dementia were USD 10.4 billion in 2016, and are expected to rise by 2031 [47].

In Manitoba alone, the total economic burden of dementia (direct health costs, unpaid caregiver costs, and indirect costs) is close to 1 billion dollars, and this amount is expected to grow to more than 28 billion by 2038 [ 25 , $26,48]$. This number is the total annual economic burden of dementia in Manitoba that is the sum of direct health costs, and opportunity costs (foregone wages) of unpaid informal caregivers and indirect costs. Due to these rising costs and the expected increase in number of dementia cases in Manitoba, it will be very challenging to provide proper healthcare and social services. Table 4 compares the global estimation of monetary costs of dementia with Canada and Manitoba.

\section{Risk Factors and Dementia}

Our current knowledge on dementia, mainly the $\mathrm{AD}$ type, shows that dementias are multifactorial disorders, in which various risk factors are involved $[16,49,50]$. The question of how risk factors affect dementia onset and disease progression needs further investigation. Within North America, as elsewhere, aging is the greatest risk factor for the prevalence of dementia $[10,51]$. The risk of dementia is expected to double every 5 years after the age of 65 [52-54]. Currently, "baby boomers" across North America have reached 51-70 years of age. According to Health Canada, the senior population in Canada is projected to increase from 3.92 million in 2001 to 9.2 million by 2041 [55]. It was reported at the 2015 Alzheimer's Association International Conference that over 28 million "baby boomers" will develop dementia between 2015 and 2050 [56]. Table 5 shows the prevalence of dementia in Canada categorized by age $(65-74,75-84$,

Neuroepidemiology 2018;51:71-81 
Table 5. Projection of dementia statistics of Canada age-wise in both sexes

\begin{tabular}{lclll}
\hline \multicolumn{4}{c}{} & \multicolumn{2}{l}{ Canada cases of dementia: both sexes } \\
\cline { 2 - 4 } & \multicolumn{2}{l}{ ages } & $\begin{array}{l}\text { total } \\
\text { cases }\end{array}$ \\
\cline { 2 - 4 } Year & $65-74$ years & $75-84$ years & $85+$ years & \\
\hline 2014 & 74,428 & 189,126 & 220,399 & 483,953 \\
2033 & 114,940 & 390,246 & 481,768 & 986,954 \\
\hline
\end{tabular}

and $85+$ years old). The overall number of cases of dementia across Canada will grow by $103.93 \%$ from 2014 to 2033 (19 years). The largest increase occurs in those aged 85 and older with a growth of $118.58 \%$ by the year 2033 , while the 75-84 age group is projected to have a $106.34 \%$ increase and the 65-74 age group a $54.41 \%$ increase.

Since age is a major factor for the onset of dementia, as the proportion of seniors in Manitoba likewise in Canada increases, the rate of dementia is expected to rise. The number of Manitobans (65+) with dementia in the year $2015(20,235)$ is expected to increase 2.3 times when compared to year $2045(47,021)$. Information in Table 6 shows the Manitoba population projection data categorized by age for 2015-2045. The overall number of cases of dementia in Manitoba will grow by $20.7 \%$ from 2015 to $2025,68.16 \%$ from 2015 to 2035 , and $125 \%$ from 2015 to 2045. The largest increase occurs in the 75-84 years old category with an increase of $98.83 \%$ by the year 2035, while the $85+$ age group shows a $61.36 \%$ increase. Given these dramatic shifts within the elderly population in Manitoba, expected increases in dementia rates will create additional pressure on Manitoba's healthcare system and society as a whole.

\section{Gender and Dementia}

Generally, dementia occurs more often in women than men, especially at older ages [52]. According to a 2014 report by the Alzheimer Society of Canada, approximately 3.2 million or two-thirds of Canadian seniors living with $\mathrm{AD}$ are women [37]. Since aging is a key risk factor for dementia, it has been suggested that more women are affected by dementia as compared with men, as women tend to outlive men [14]. However, this notion is controversial and more sex- and gender-based research is needed to address this statistic. For example, rapid decreases in sex hormones at menopause increase the risk of dementia in elderly women [57]. Another risk factor is a
Table 6. Projection of dementia statistics of Manitoba age-wise in both sexes

\begin{tabular}{lcccc}
\hline Age & Year 2015 & Year 2025 & Year 2035 & Year 2045 \\
\hline $45-64$ & 1,638 & 1,702 & 1,830 & 2,144 \\
$65-74$ & 2,449 & 3,418 & 3,778 & 3,751 \\
$75-84$ & 6,597 & 9,155 & 13,116 & 14,726 \\
$85+$ & 11,190 & 12,126 & 18,057 & 28,544 \\
\hline Total & 21,874 & 26,401 & 36,782 & 49,166 \\
\hline
\end{tabular}

genetic linkage to the APOE gene. Several studies reported a positive correlation between the presence of one or more APOE-e4 alleles and neuritic plaques in AD [58, 59]. Furthermore, research has shown that females carrying a copy of the APOE-e4 gene possess a $7-10 \%$ greater risk of developing Alzheimer's as compared with men $[60,61]$. Unlike AD, LBD, VaD, and PDD are more likely to affect men than women [62-64]. Although some dementias are more common as well as more severe in women, the mechanisms associated with gender differences are not well understood.

The Alzheimer Society of Canada estimated that the prevalence of dementia in females is higher than males with a ratio of approximately $65 \%$ in 2014 that decreases slowly over the years to $61 \%$ in 2033 . The estimated proportion of men with dementia in Canada is expected to increase from $35 \%$ in 2014 to $39 \%$ in 2033 (Table 7).

Figures 2 and 3 provide information about the prevalence rates that are applied to the Manitoba population projection data 2012-2048, age-wise and sex-wise. The number of new cases of dementia is increasing over time. The proportion of women diagnosed with dementia, who are over the age of 85 , is expected to increase from $40.95 \%$ in 2015 to $41.25 \%$ in 2045 ; there is no perceptible change over the 30 year period. The prevalence of dementia is higher in females than in males with a ratio of approximately $1.96 \%$ in 2015 that decreases slowly over the years to $1.66 \%$ in $2025,1.51 \%$ in 2035 and $1.44 \%$ in 2045 . What is responsible for the increasing rates in men and decreasing rates in women is not clear, but one possibility is that men are expected to live longer, given improvements in health care and decreases in other age-related chronic illnesses.

\section{Indigenous People and Dementia}

According to Statistics Canada, the population of Indigenous peoples in Canada from 2006 to 2011 increased $20.1 \%$ compared with $5.2 \%$ [65] for non-Indig-
Adlimoghaddam/Roy/Albensi 


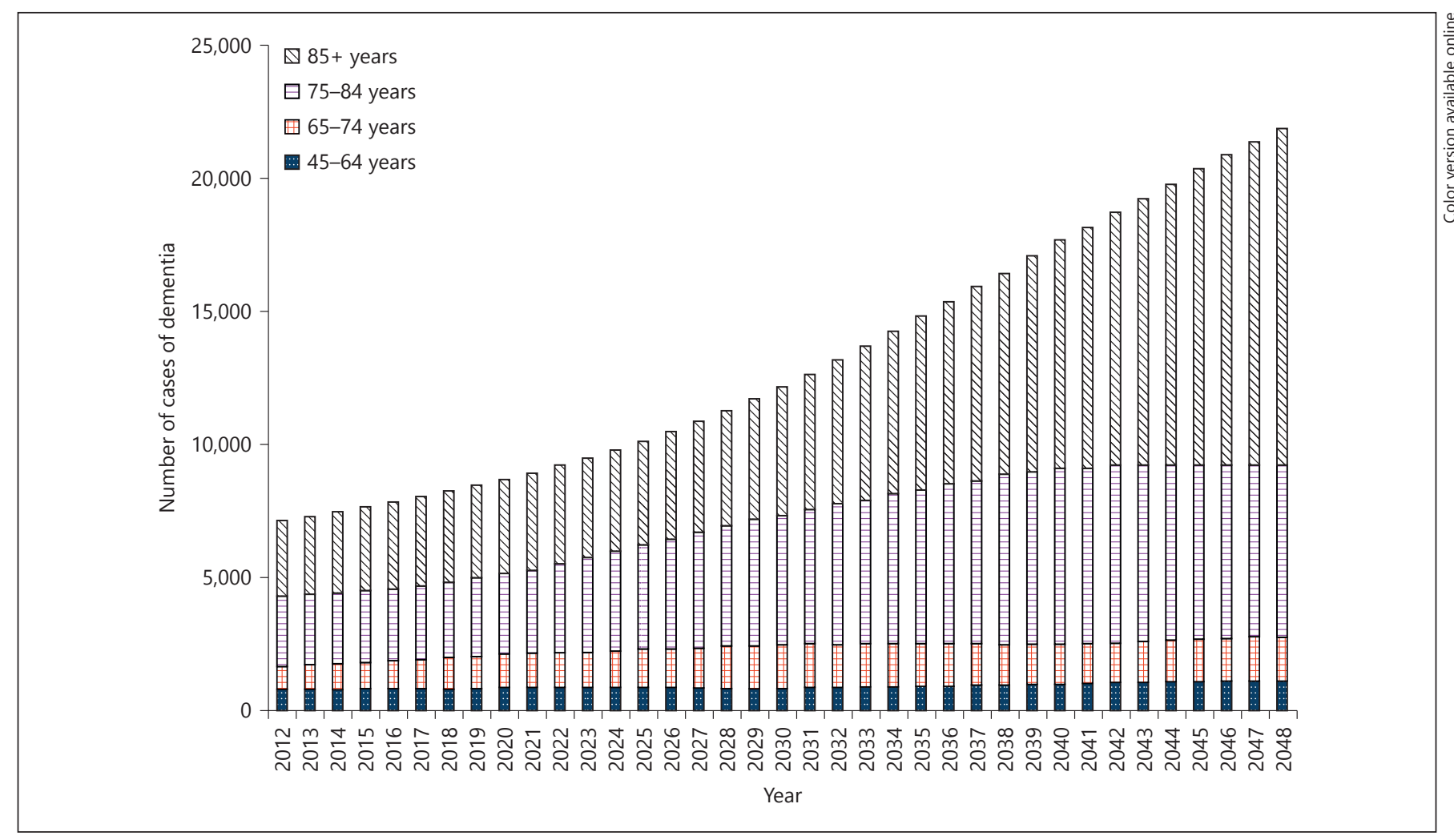

Fig. 2. Projection of dementia statistics of Manitoba (45+) gender-wise in males.

Table 7. Projection of dementia statistics of Canada (65+) gender-wise in both sexes

\begin{tabular}{|c|c|c|c|c|}
\hline \multirow[b]{2}{*}{ Year } & \multicolumn{3}{|l|}{ Ages } & \multirow{2}{*}{$\begin{array}{l}\text { Total } \\
\text { cases }\end{array}$} \\
\hline & $65-74$ years & $75-84$ years & $85+$ years & \\
\hline \multicolumn{5}{|c|}{ Canada cases of dementia: females } \\
\hline 2014 & 45,618 & 110,304 & 179,453 & 335,357 \\
\hline 2033 & 69,549 & 217,523 & 316,686 & 603,758 \\
\hline \multicolumn{5}{|c|}{ Canada cases of dementia: males } \\
\hline 2014 & 28,810 & 78,822 & 70,946 & 178,578 \\
\hline 2033 & 45,391 & 172,723 & 165,082 & 383,196 \\
\hline
\end{tabular}

enous Canadians. In 2016, 1.6 million or $4.9 \%$ of the total Canadian population identified as Indigenous people [65]. Approximately, 6\% of the total Indigenous population was 65 years and older. This percentage is almost half of the non-Indigenous senior population (14.2\%). Table 8 shows the number and distribution of Indigenous people in all provinces and territories in Canada (2011). Approximately $14 \%$ of the total Indigenous populations in Canada live in Manitoba (Table 8) [65]. Particularly, Winnipeg has the largest Indigenous population who live mostly off reserves with a population of 25,970 compared to Edmonton and Vancouver with a population of 18,210 and 15,080 respectively [65].

Since dementia is a growing public health concern, it important to examine potential differences in the experience of dementia within Indigenous communities. According to most Indigenous peoples of Canada, dementia is not considered a health problem; rather Indigenous people tend to consider dementia as non- 


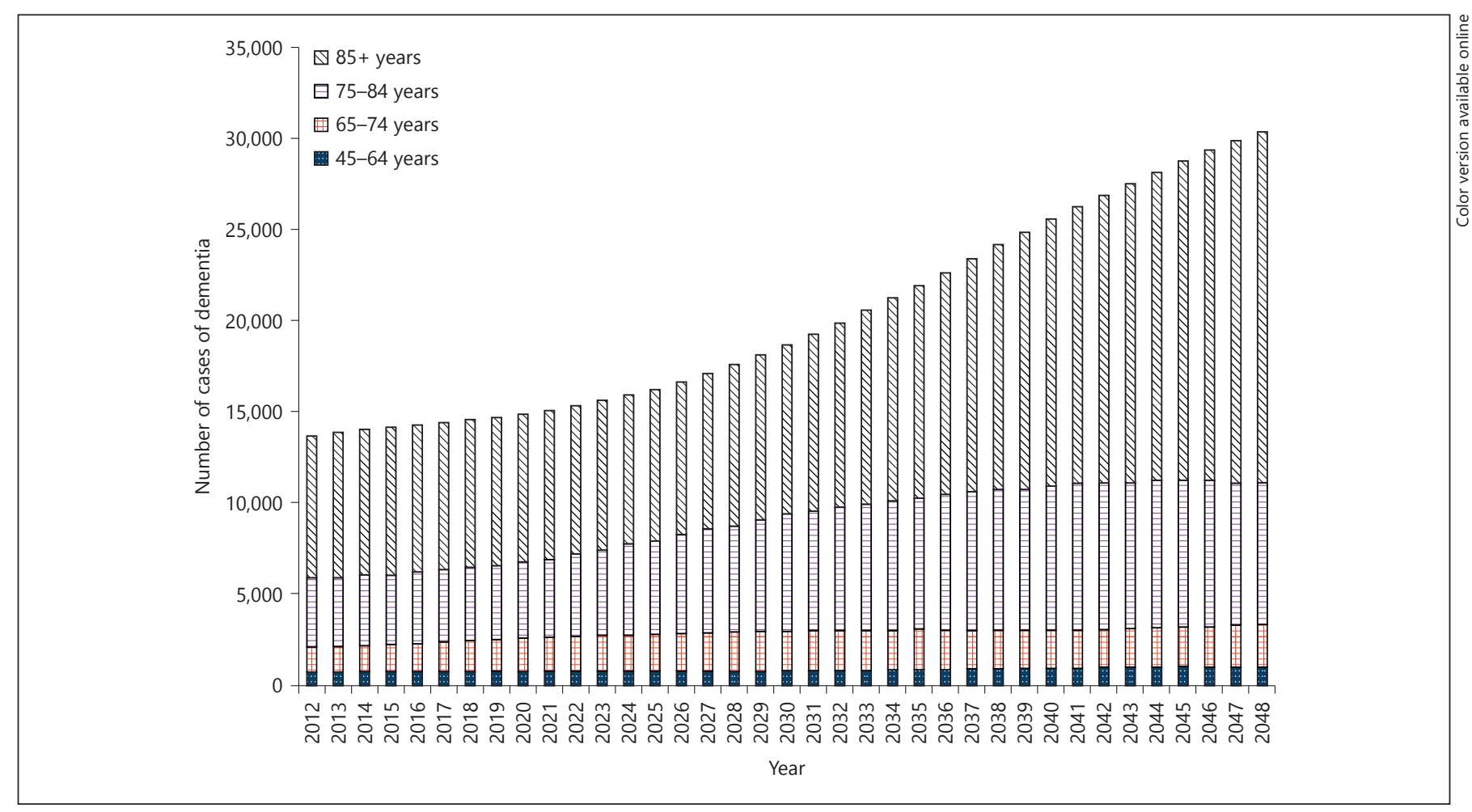

Fig. 3. Projection of dementia statistics of Manitoba (45+) gender-wise in females.

Table 8. Distribution of the Indigenous population in all provinces and territories of Canada in 2011 [65]

\begin{tabular}{lrrr}
\hline Provinces and territories & $\begin{array}{c}\text { Indigenous } \\
\text { population }\end{array}$ & $\begin{array}{l}\text { Indigenous population } \\
\text { as percentage of } \\
\text { the total population }\end{array}$ & $\begin{array}{c}\text { Percentage of } \\
\text { distribution }\end{array}$ \\
\hline Newfoundland and Labrador & 35,800 & 7.1 & 2.6 \\
Prince Edward Island & 2,230 & 1.6 & 0.2 \\
Nova Scotia & 33,845 & 3.7 & 2.4 \\
New Brunswick & 22,615 & 3.1 & 1.6 \\
Quebec & 141,915 & 1.8 & 10.1 \\
Ontario & 301,425 & 2.4 & 21.5 \\
Manitoba & 195,900 & 16.7 & 14.0 \\
Saskatchewan & 157,740 & 15.6 & 1.3 \\
Alberta & 220,695 & 6.2 & 15.8 \\
British Columbia & 232,290 & 5.4 & 0.6 \\
Yukon & 7,705 & 23.1 & 1.5 \\
Northwest Territories & 21,160 & 51.9 & 2.0 \\
Nunavut & 27,360 & 86.3 & 100.0 \\
Canada & $1,400,685$ & 4.3 & \\
\hline
\end{tabular}

pathological brain aging $[66,67]$. The prevalence of dementia in the Indigenous population in Canada has not been well defined. One study found that dementia is more prevalent among Indigenous peoples in Alberta as compared to non-Indigenous individuals [68]. Re- cent studies show that modifiable risk factors (e.g., hypertension, physical inactivity, diabetes, obesity, and smoking) are strongly related with increased AD risk. It is known that indigenous peoples in Canada have higher prevalence of modifiable risk factors compared 
to their non-Indigenous counterparts [30]. These differences are more in Indigenous people who live on reserve. It is likely that environmental, socioeconomic, and sociocultural factors are associated with the increased rate of $\mathrm{AD}$ among Indigenous peoples in Canada [30].

Overall, available information about the prevalence and incidence of all types of dementia among Indigenous population of Canada is very minimal. This lack of information is anticipated to be a critical challenge for federal and provincial healthcare systems as they strive to provide services to the population [68]. By expanding our knowledge on the impact of dementia on Indigenous people and communities, one could advocate for greater resources for culturally suitable strategies to reduce risk factors for dementia, as well as to assist communities in providing care for individuals affected by these diseases.

\section{Type-2 Diabetes and Dementia}

Type- 2 diabetes is a metabolic disorder where the ability to produce or to respond to the hormone insulin is impaired. As a result, there are high blood sugar levels over a prolonged period, which leads to pathology [69]. According to the Canadian Diabetes Association, in 2016, 29\% of Canadian's had type-2 diabetes and this number is expected to rise by $33 \%$ in 2026 [70]. Moreover, in Manitoba approximately 94,000 people are living with type- 2 diabetes and this number is projected to increase to 139,000 by 2020 [71]. Type- 2 diabetes is one of the important modifiable risk factors for dementia $[72,73]$. Research suggests that the rate of cognitive decline is accelerated in aged people with dementia and type- 2 diabetes $[74,75]$. Interestingly, it has been shown that accumulation of $\mathrm{A} \beta$ plaques interferes with insulin receptors in the AD brain and causes brain cells to become unresponsive to insulin [76-78]. Several factors that may be involved in the linkage between diabetes and dementia include brain white matter structural changes, hyperinsulinaemia, glycemic index changes, increased rate of stroke, metabolic syndrome, cross-association of type- 2 diabetes and obesity, and genetic factors such as APOE-e4 [79-83]. To date, the linkage between type- 2 diabetes and dementia is not wellunderstood $[69,84,85]$. Early studies indicated a low rate of type- 2 diabetes in $\mathrm{AD}$ patients $[86,87]$; however, more recent studies have reported evidence that show that type-2 diabetes increased the risk of develop-

Future Trends and the Economic Burden of Dementia in Manitoba ing dementia [74, 81, 83, 88-95]. These differences may be related to the definition of dementia, the stage of dementia, the age range of individuals, and/or the method used to measure dementia status [95]. It is estimated that the rate of elderly people with diabetes is predicted to increase significantly over the next few decades [96]. Therefore, more studies will be required to acquire a better understanding of risk factors, mediators, and/or mechanisms that link dementia and type-2 diabetes.

\section{Conclusions and Recommendations}

The number of Manitobans living and affected by dementia has dramatically increased, especially for those aged 65 and above. The largest increase is projected to occur in the 75-84 years of age group with a growth of $98.83 \%$ by the year 2035 , while for ages $85+$ a $61.36 \%$ increase is estimated.

The prevalence of $85+$ men identified with dementia is also expected to rise from $31.4 \%$ in 2015 to $79 \%$ in 2045 , which is a shift from past statistics. The prevalence of dementia in women (85+) is expected to rise from $40.95 \%$ in 2015 to $41.25 \%$ in 2045 , which is not a remarkable change over the long period.

These results strongly suggest that Manitobans must urge their government and other key stakeholders to take action now and confront the challenge of controlling the dementia epidemic. The future projections presented here need immediate attention. It is strongly recommended that national and provincial strategies be created and acted upon. Action items would include increased dementia awareness, promotion of preventative strategies, and increased funding to support dementia research and care [10].

\section{Acknowledgments}

The data presented in this review were taken from several sources, but primarily from the Manitoba Bureau of Statistics (MBS). All sources are referenced below. This work was funded by Research Manitoba (Dr. Aida Adlimoghaddam), the Alzheimer's Society of Manitoba, and the St. Boniface Hospital Research Foundation (to BCA). BCA is a Research Affiliate at the University of Manitoba's Centre on Aging and holds the Honourable Douglas Everett, Patricia Everett and the Royal Canadian Properties Endowment Fund Chair and the Manitoba Dementia Research Chair. We thank Drs. Campbell, St. John, and Millikin and also Ms. Wendy Schettler (CEO-Alzheimer's Society of Manitoba) for a critical reading of the manuscript. 


\section{References}

1 Wells CE: Dementia: definition and description. Contemp Neurol Ser 1977;15:1-14.

2 Brayne C, et al: Incidence of clinically diagnosed subtypes of dementia in an elderly population. Cambridge project for later life. Br J Psychiatry 1995;167:255-262.

3 Roman GC, et al: Vascular dementia: diagnostic criteria for research studies. Report of the NINDS-AIREN International Workshop. Neurology 1993;43:250-260.

4 Drachman DA: New criteria for the diagnosis of vascular dementia: do we know enough yet? Neurology 1993;43:243-245.

5 Neary D, Snowden J: Fronto-temporal dementia: nosology, neuropsychology, and neuropathology. Brain Cogn 1996;31:176187.

6 McKeith IG, et al: Consensus guidelines for the clinical and pathologic diagnosis of dementia with Lewy bodies (DLB): report of the consortium on DLB international workshop. Neurology 1996;47:1113-1124.

7 Cummings JL: Intellectual impairment in Parkinson's disease: clinical, pathologic, and biochemical correlates. J Geriatr Psychiatry Neurol 1988;1:24-36.

8 Cummings JL: Treatment of Alzheimer's disease: current and future therapeutic approaches. Rev Neurol Dis 2004;1:60-69.

9 Cummings JL: Alzheimer's disease. N Engl J Med 2004;351:56-67.

10 Ferri CP, et al: Global prevalence of dementia: a Delphi consensus study. Lancet 2005;366: 2112-2117.

11 World Health Organization: Dementia: A Public Health Priority, 2012.

12 International World Health Organization. Alzheimer's Disease International: Dementia: A Public Health Priority. Mental Health, 2012.

13 Wimo A, Winblad B, Aguero-Torres H, von Strauss E: The magnitude of dementia occurrence in the world. Alzheimer Dis Assoc Disord 2003;17:63-67.

14 Qiu C, De Ronchi D, Fratiglioni L: The epidemiology of the dementias: an update. Curr Opin Psychiatry 2007;20:380-385.

15 Canadian study of health and aging: study methods and prevalence of dementia. CMAJ 1994;150:899-913.

16 Lindsay JH, Hébert R, Rockwood K: The Canadian study of health and aging: risk factors for vascular dementia. Stroke 1997;28:526530.

17 Yaffe K, et al: Effect of socioeconomic disparities on incidence of dementia among biracial older adults: prospective study. BMJ 2013; 347:f7051

18 Russ TC, Batty GD, Hearnshaw GF, Fenton C, Starr JM: Geographical variation in dementia: systematic review with meta-analysis. Int J Epidemiol 2012;41:1012-1032.

19 Alzheimer Society of Canada: Prevalence and Monetary Costs of Dementia in Canada. Toronto, Alzheimer Society of Canada, 2016.
20 Savva GM, et al: Age, neuropathology, and dementia. N Engl J Med 2009;360:2302-2309.

21 Sachdev PS, et al: The prevalence of mild cognitive impairment in diverse geographical and ethnocultural regions: the COSMIC collaboration. PLoS One 2015;10:e0142388.

22 Smith EE, et al: Magnetic resonance imaging white matter hyperintensities and brain volume in the prediction of mild cognitive impairment and dementia. Arch Neurol 2008; 65:94-100.

23 Staekenborg SS, et al: Progression of mild cognitive impairment to dementia: contribution of cerebrovascular disease compared with medial temporal lobe atrophy. Stroke 2009; 40:1269-1274.

24 Manitoba Centre for Health Policy and Martens P: Patterns of Regional Mental Illness Disorder Diagnoses and Service Use in Manitoba: A Population-Based Study. Winnipeg, Centre for Health Policy, 2004.

25 Smetanin P, et al: Rising Tide: The Impact of Dementia in Manitoba 2008 to 2038. RiskAnalytica, 2009.

26 Statistics MB: Population Projection by Sex and Age, 2012-2048, 2015.

27 Canada S: Aboriginal Peoples: Fact Sheet for Manitoba, 2016.

28 Naqshbandi M, Harris SB, Esler JG, Antwi-Nsiah F: Global complication rates of type 2 diabetes in Indigenous peoples: a comprehensive review. Diabetes Res Clin Pract 2008;82:1-17.

29 Canadian Diabetes Association Clinical Practice Guidelines Expert Committee, et al: Pharmacologic management of type 2 diabetes. Can J Diab 2013;37(suppl 1):S61-S68.

30 MacDonald JP, Barnes DE, Middleton LE: Implications of risk factors for Alzheimer's disease in Canada's indigenous population. Can Geriatr J 2015;18:152-158.

31 Chappell NL, Hollander MJ: An evidencebased policy prescription for an aging population. Healthc Pap 2011;11:8-18.

32 Browning JS, Schwirian PM: Spousal caregivers' burden: impact of care recipient health problems and mental status. J Gerontol Nurs 1994;20:17-22.

33 Brodaty H, Donkin M: Family caregivers of people with dementia. Dialogues Clin Neurosci 2009;11:217-228.

34 The Canadian Study of Health and Aging: Risk factors for Alzheimer's disease in Canada. Neurology 1994;44:2073-2080.

35 Hepburn KW, Tornatore J, Center B, Ostwald SW: Dementia family caregiver training: affecting beliefs about caregiving and caregiver outcomes. J Am Geriatr Soc 2001; 49:450-457.

36 Families care: Alzheimer's Caregiving in the United States. Chicago, Alzheimer's Association and National Alliance for Caregiving, 2004.

37 Canada: The Aproaching Tsunami of Alzheimer's Disease and Dementia, 2013.

38 Authority WRH, 2015.
39 Wimo A, et al: The economic impact of dementia in Europe in 2008-cost estimates from the Eurocode project. Int J Geriatr Psychiatry 2011;26:825-832.

40 Wimo A, et al: The worldwide economic impact of dementia 2010. Alzheimers Dement 2013;9:1-11.e13.

41 Reports, W. A., 2010.

42 Wimo A, et al: The worldwide costs of dementia 2015 and comparisons with 2010. Alzheimers Dement 2017;13:1-7.

43 Public Health Agency of Canada: Economic Burden of Illness in Canada. 2014, Public Health Agency of Canada, 2005-2008.

44 Mental Health Commission of Canada: Making the Case for Investing in Mental Health in Canada. Calgary, Mental Health Commission of Canada, 2011.

45 Public Health Agency of Canada: Economic Burden of Illness in Canada. Ottawa, Public Health Agency of Canada, 2014.

46 Alzheimer Society of Canada: Rising Tide: The Impact of Dementia on Canadian Society. Toronto, Alzheimer Society of Canada, 2010.

47 Public Health Agency of Canada: Mapping Connections: An Understanding of Neurological Conditions - The National Population Health Study of Neurological Conditions in Canada Public Health Agency of Canada, 2014.

48 Statistics, M. B., 2015.

49 The Canadian study of health and aging: risk factors for Alzheimer's disease in Canada. Neurology 1994;44:2073-2080.

50 Hebert R, et al: Vascular dementia: incidence and risk factors in the Canadian study of health and aging. Stroke 2000;31:1487-1493.

51 Fratiglioni L, De Ronchi D, Aguero-Torres $\mathrm{H}$ : Worldwide prevalence and incidence of dementia. Drugs Aging 1999;15:365-375.

52 Derreberry TM, Holroyd S: Dementia in women. The psychiatric clinics of North America 2017;40:299-307.

53 Brody JA: Prospects for an ageing population. Nature 1985;315:463-466.

54 Monroe RT: The effect of aging of population on general health problems. N Engl J Med 1953;249:322-328.

55 Canada, H., 2011.

56 Alzheimer's Association International Conference: New Analysis Shows More Than 28 Million Baby Boomers Will Develop Alzheimer's Disease; Will Consume Nearly 25\% of Medicare Spending, 2015.

57 Riggs BL, Khosla S, Melton LJ 3rd: A unitary model for involutional osteoporosis: estrogen deficiency causes both type I and type II osteoporosis in postmenopausal women and contributes to bone loss in aging men. J Bone Miner Res 1998;13:763-773.

58 Tiraboschi P, et al: Impact of APOE genotype on neuropathologic and neurochemical markers of Alzheimer disease. Neurology 2004;62:1977-1983. 
59 Schmechel DE, et al: Increased amyloid betapeptide deposition in cerebral cortex as a consequence of apolipoprotein $\mathrm{E}$ genotype in late-onset Alzheimer disease. Proc Natl Acad Sci U S A 1993;90:9649-9653.

60 Begum AN, et al: Women with the Alzheimer's risk marker ApoE4 lose $\mathrm{A} \beta$-specific $\mathrm{CD} 4^{+}$ T cells 10-20 years before men. Transl Psychiatry 2014;4:e414.

61 Genin E, et al: APOE and Alzheimer disease: a major gene with semi-dominant inheritance. Mol Psychiatry 2011;16:903-907.

62 Hughes TA, et al: A 10-year study of the incidence of and factors predicting dementia in Parkinson's disease. Neurology 2000;54: 1596-1602.

63 McKeith IG, et al: Diagnosis and management of dementia with Lewy bodies: third report of the DLB Consortium. Neurology 2005;65:1863-1872.

64 Nelson NW: Differential diagnosis of $\mathrm{Al}$ zheimer's dementia and vascular dementia. Dis Mon 2007;53:148-151.

65 Statistics Canada: Aboriginal Peoples in Canada: First Nations People, Métis and Inuit, 2011.

66 Kramer JH, Duffy JM: Aphasia, apraxia, and agnosia in the diagnosis of dementia. Dementia 1996;7:23-26.

67 Henderson JN, Traphagan JW: Cultural factors in dementia: perspectives from the anthropology of aging. Alzheimer Dis Assoc Disord 200;19:272-274.

68 Jacklin KM, Walker JD, Shawande M: The emergence of dementia as a health concern among First Nations populations in Alberta, Canada. Can J Public health 2012;104:e39-e44.

69 Strachan MW, Deary IJ, Ewing FM, Frier BM Is type II diabetes associated with an increased risk of cognitive dysfunction? A critical review of published studies. Diabetes Care 1997; 20:438-445.

70 Canadian Diabetes Association: Diabetes in Canada, 2016.

71 Canadian Diabetes Association: Diabetes in Manitoba, 2016.

72 Luchsinger JA, Tang MX, Stern Y, Shea S, Mayeux R: Diabetes mellitus and risk of $\mathrm{Al}$ zheimer's disease and dementia with stroke in a multiethnic cohort. Am J Epidemiol 2001; 154:635-641.

73 Schnaider Beeri M, et al: Diabetes mellitus in midlife and the risk of dementia three decades later. Neurology 2004;63:1902-1907.

74 Leibson CL, et al: The risk of dementia among persons with diabetes mellitus: a population- based cohort study. Ann N Y Acad Sci 1997; 826:422-427.

75 Yaffe K, et al: Diabetes, impaired fasting glucose, and development of cognitive impairment in older women. Neurology 2004;63: 658-663.

76 Rasgon NL, et al: Insulin resistance and hippocampal volume in women at risk for $\mathrm{Al}$ zheimer's disease. Neurobiol Aging 2011;32: 1942-1948.

77 Talbot K, et al: Demonstrated brain insulin resistance in Alzheimer's disease patients is associated with IGF-1 resistance, IRS-1 dysregulation, and cognitive decline. J Clin Invest 2012;122:1316-1338

78 Haroon NN, et al: Risk of dementia in seniors with newly diagnosed diabetes: a populationbased study. Diabetes Care 2015;38:18681875.

79 Luchsinger JA, Patel B, Tang MX, Schupf N, Mayeux R: Measures of adiposity and dementia risk in elderly persons. Arch Neurol 2007; 64:392-398.

80 Beydoun MA, et al: Association of adiposity status and changes in early to mid-adulthood with incidence of Alzheimer's disease. Am J Epidemiol 2008;168:1179-1189.

81 Kivipelto M, et al: Midlife vascular risk factors and Alzheimer's disease in later life: longitudinal, population based study. BMJ 2001;322: 1447-1451.

82 Kanaya AM, Barrett-Connor E, Gildengorin G, Yaffe K: Change in cognitive function by glucose tolerance status in older adults: a 4-year prospective study of the Rancho Bernardo study cohort. Arch Intern Med 2004; 164:1327-1333.

83 Peila R, Rodriguez BL, Launer LJ; HonoluluAsia Aging Study: Type 2 diabetes, APOE gene, and the risk for dementia and related pathologies: The Honolulu-Asia aging study. Diabetes 2002;51:1256-1262.

84 Allen KV, Frier BM, Strachan MW: The relationship between type 2 diabetes and cognitive dysfunction: longitudinal studies and their methodological limitations. Eur J Pharmacol 2004;490:169-175.

85 Awad N, Gagnon M, Messier C: The relationship between impaired glucose tolerance, type 2 diabetes, and cognitive function. J Clin Exp Neuropsychol 2004;26:10441080

86 Nielson KA, et al: Apolipoprotein-E genotyping of diabetic dementia patients: is diabetes rare in Alzheimer's disease? J Am Geriatr Soc 1996;44:897-904.
87 Bucht G, Adolfsson R, Lithner F, Winblad B: Changes in blood glucose and insulin secretion in patients with senile dementia of $\mathrm{Al}$ zheimer type. Acta Med Scand 1983;213: 387-392.

88 Wolf H, Gertz HJ: [Vascular dementia - diagnosis, prevention and treatment]. Psychiatr Prax 2004;31:330-338.

89 McVeigh C, Passmore P: Vascular dementia: prevention and treatment. Clin Intervent Aging 2006;1:229-235.

90 MacKnight C, Rockwood K, Awalt E, McDowell I: Diabetes mellitus and the risk of dementia, Alzheimer's disease and vascular cognitive impairment in the Canadian study of health and aging. Dement Geriatr Cogn Disord 2002;14:77-83.

91 Hassing LB, et al: Diabetes mellitus is a risk factor for vascular dementia, but not for Alzheimer's disease: a population-based study of the oldest old. Int Psychogeriatr 2002;14: 239-248.

92 Ott A, et al: Diabetes mellitus and the risk of dementia: the Rotterdam study. Neurology 1999;53:1937-1942.

93 Leibson CL, et al: Risk of dementia among persons with diabetes mellitus: a population-based cohort study. Am J Epidemiol 1997;145:301-308.

94 Moreira PI: High-sugar diets, type 2 diabetes and Alzheimer's disease. Curr Opin Clin Nutr Metab Care 2013;16:440-445.

95 Ravona-Springer R, et al: Diabetes is associated with increased rate of cognitive decline in questionably demented elderly. Dement Geriatr Cogn Disord 2010;29:68-74.

96 Zimmet P, Alberti KG, Shaw J: Global and societal implications of the diabetes epidemic. Nature 2001;414:782-787.

97 Alzheimer Society Report: Dementia numbers in Canada, 2015.

98 World Health Organization: Dementia, 2016.

99 Public Health Agency of Canada: Mapping Connections: An Understanding of Neurological Conditions in Canada-The National Population Health Study of Neurological Conditions. Ottawa, Public Health Agency of Canada, 2014.

100 Alzheimer Society of Canada: Revised Dementia Statistics (Rising Tide 2.0). Toronto, Alzheimer Society of Canada, 2012.

101 Alzheimer Society of Canada: Prevalence and Monetary Costs of Dementia in Canada. Toronto, Alzheimer Society of Canada, 2016. 